Copyright by the American Society of Agricultural and Biological Engineers. Shukla, S.; Mostaghimi, S.; Lovern, S. B.; McClellan, P. W., "Impact of agrichemical facility best management practices on runoff water quality," Transactions of the ASAE. Vol. 44(6): 1661-1672. (doi: 10.13031/2013.7042) @2001

\title{
ImPaCt of Agrichemical Facility Best Management Practices on RunOfF WATER Quality
}

\author{
S. Shukla, S. Mostaghimi, S. B. Lovern, P. W. McClellan
}

\begin{abstract}
Water quality effects of structural and managerial BMPs implemented at an agrichemical mixing and handling facility, located in an agricultural watershed in Virginia, were investigated in this study. The measured water quality parameters include two commonly used pesticides (atrazine and metolachlor), nitrogen $(N)$, and phosphorus (P). BMPs implemented include: pesticide mixing and loading concrete pad with a sump and pump fitting; a variety of runoff diversion structures to divert the rooftop runoff away from the critical areas; structures to contain transport of chemicals to the drainage leaving the facility; and recycling of rinsate by applying it on the agricultural land. Concentration of pesticides and nutrients were measured at the facility outlet as well as the outlet of the main watershed in which the facility was located. Implementation of BMPs resulted in drastic reduction in mean concentrations of the two pesticides in the stream leaving the facility as well as in the main watershed stream. Maximum atrazine concentrations in the drainage leaving the facility reduced from 17,389 $\mu \mathrm{g} / \mathrm{l}$ during the pre-BMP period (1986-1988) to 1,452 $\mu \mathrm{g} / \mathrm{l}$ during the post-BMP period (1989-1996). The post-BMP mean concentrations of atrazine and metolachlor at the facility outlet were reduced by $94 \%$ (2690 $\mu \mathrm{g} / \mathrm{l}$ to $166 \mu \mathrm{g} / \mathrm{l}$ ) and $91 \%$ (4579 $\mu \mathrm{g} / \mathrm{l}$ to $402 \mu \mathrm{g} / \mathrm{l})$, respectively. The corresponding post-BMP reductions in concentration at the main watershed outlet were $52 \%$ and $78 \%$ for atrazine and metolachlor, respectively. Nonparametric trend tests results indicated statistically significant downward trend and reduced post-BMP concentrations of the two pesticides at the facility as well as the watershed outlets. Impact of BMPs on the nutrient concentrations were not clear due to large nutrient contributions from animal production activities in upland areas of the watershed. Results from this study will provide needed impetus for implementation of BMPs at other agrichemical mixing and handling facilities in Virginia as well as other states to drastically reduce the transport of pesticides and nutrients to surface water bodies.
\end{abstract}

Keywords. BMPs, Atrazine, Metolachlor, Nitrogen, Phosphorus, Mixing and handling plants.

W

idespread use of agricultural chemicals during the last three decades has contributed to the pollution of surface as well as ground waters (Lounsbury, 1992). Nutrient and pesticide loadings into estuaries such as the Chesapeake Bay have become serious problems (NRC, 1993). Nonpoint source pollutants, transported primarily by runoff, have been one of the major causes of the decline of the Chesapeake Bay. Agricultural nonpoint source pollution affects $76 \%$ of lakes, $65 \%$ of streams, and $45 \%$ of estuaries in the U.S. (Senseman et al., 1997). Although most of the contamination from agrichemicals is nonpoint in nature, point sources such

Article was submitted for review in January 2001; approved for publication by the Soil \& Water Division of ASAE in July 2001.

This research was supported by the Virginia Department of Conservation and Recreation, Division of Soil and Water Conservation, Richmond, and the Florida Agricultural Experiment Station, and approved for publication as Journal Series No. R-08628.

The authors are Sanjay Shukla, ASAE Member Engineer, Assistant Professor, Agricultural and Biological Engineering Department, University of Florida, SWFREC, Immokalee, Florida; Saied Mostaghimi, ASAE Member Engineer, H. E. and Elizabeth F. AlphinProfessor, and Sharla B. Lovern, Research Assistant, Biological Systems Engineering Department, Virginia Tech, Blacksburg, Virginia; and Phillip W. McClellan, President, MapTech Inc., Corporate Research Center, Virginia Tech, Blacksburg, Virginia. Corresponding author: Saied Mostaghimi, Biological Systems Engineering Dept, 308 Seitz Hall, Virginia Tech, Blacksburg, VA 24061-0303; phone: 540-231-7605; fax: 540-231-3199; e-mail: smostagh@vt.edu. as those originating from agrichemical dealerships and accidental spills could also contribute to water quality problems.

Pesticides are one of the major sources of water pollution in the United States (CAST, 1994). The majority of pesticides contaminating water bodies originate from either their application to agricultural lands or their accidental and incidental spillage at agrichemical mixing and handling facilities (Lounsbury, 1992). Among the pesticides used in the U.S., atrazine and metolachlor are the most widely used. They are also widely used in Virginia and have been detected in both surface water and ground water in various parts of the state (U.S. EPA, 1994b).

Pesticides play an important role in modern agricultural production. Of all the pesticides currently in use, herbicides constitute the greatest amount (US EPA, 1994b). Although some herbicides are acutely toxic to fish, the hazard of herbicides to aquatic environment is much smaller than insecticides (Leonard, 1990). Depending on the chemical composition and their concentration in surface water, herbicides present in surface water bodies can produce undesirable effects by destroying or suppressing aquatic vegetation. Consider, for example, the case of atrazine, the most widely used herbicide in the U.S. (US EPA, 1994b). In two separate studies, Forney and Davis (1981) and Kemp et al. (1982) reported that growth of submerged aquatic vegetation was inhibited in the presence of 60 to $1040 \mu \mathrm{g} / \mathrm{l}$ (ppb) of atrazine. In these two studies, atrazine concentrations of less than $10 \mu \mathrm{g} / \mathrm{l}$ did not cause any damage to the 
aquatic vegetation. Major environmental concerns from pesticides arise from their presence in the ground water since much of the population depends on ground water for drinking (NRC, 1986; Leonard, 1990). However, due to close interaction between surface and ground water, pesticide residues present in surface water may affect the ground water. In certain hydrologic settings where surface water replenishes the ground water, pesticides present in surface water may move to the ground water making it a matter of concern.

Nutrients (nitrogen and phosphorus) are another class of agricultural chemicals that are known to have damaging effects on water quality. Nitrogen $(\mathrm{N})$ and phosphorus $(\mathrm{P})$ can stimulate excessive algae growth, which in turn suppresses submerged aquatic vegetation through increased turbidity and decreased sunlight availability. With algae decay, the oxygen availability for other living organisms diminishes resulting in potential for fish kills and for adverse effects on the quality of species composition.

The transport of pesticide and nutrients to surface water bodies depends on a variety of factors such as source (point or nonpoint), soil and hydrologic properties at the site of application or spill, prevailing weather conditions (rainfall, wind velocity, humidity, and temperature) and chemical properties (biochemical degradation, vapor pressure, sorption, and solubility). While nonpoint sources of $\mathrm{N}, \mathrm{P}$, and pesticides deserve greater attention with regard to managing the loadings, point sources of these pollutants are also important because they can cause unusually high concentrations of pesticides in surface water bodies. For example, concentrations of pesticides such as alachlor in runoff, originating from agricultural land, is usually in the range of 0 to $10 \mu \mathrm{g} / \mathrm{l}$ (Chesters et al., 1989). On the other hand, point sources such as agrichemical dealerships included in this study can potentially contribute to concentrations of pesticides such as atrazine to more than $2500 \mu \mathrm{g} / \mathrm{l}$ (800 times the health advisory level of $3 \mu \mathrm{g} / \mathrm{l}$ for atrazine).

Agrichemical facilities represent high risks for point source contamination of surface and ground waters due to the concentration, quantity and type of products at these sites (Kammel, 1995). Incidental contamination of surface water results from improper storage and/or routine activities within agrichemical facilities including mixing of pesticides and fertilizers, and washing of spray equipment (Buzicky et al., 1992). In addition to being a threat to the environment, chemical losses from these facilities also contribute to economic loss to the agrichemical dealerships. Prohibitive costs of site remediation at agrichemical facilities, where significant amount of pesticide spill/losses may have occurred, clearly justify the prevention compared to remediation approach. Consider, for example, a study by the Minnesota Department of Agriculture which estimated that approximately $50 \%$ to $60 \%$ of Minnesota's agrichemical facilities with pesticide contaminated soils could be remediated for up to $\$ 50,000$ each, while another $20 \%$ would cost more than \$200,000 each and sometimes over \$1 million each (U.S. EPA, 1994a). In contrast, costs for preventive measures could be less than $\$ 35,000$.

Site improvement is one aspect of BMPs that can help prevent chemical losses from these facilities. Implementation of agrichemical best management practices (BMPs) are encouraged by state and federal governments through educational programs, technical assistance, and cost-share incentives. Typical BMPs used to reduce the loss of chemicals from agrichemical handling facilities include: a storm water management plan; installation of secondary containment structures for bulk chemical tank, other storage areas, and equipment loading and cleaning areas; protective dikes; and pumps leading to rinse water tanks (Hoffman and Cook, 1993). These BMPs reduce runoff and erosion from the site, and thus reduce the off-site transport of chemicals.

Few studies have been performed to investigate the status of the pollution prevention practices at these facilities and their effects on water quality. A study in Illinois found that routine incidental spills and lack of containment structures were contributing to pollution of the nearby surface waters (Ackerman and Taylor, 1992). Similar point sources may exist in other states, including Virginia. In a survey study of 160 chemical facilities in Virginia, Mostaghimi et al. (1996) found that the presence of secondary containment structures was related to the age of the facility. The study also concluded that about $80 \%$ of the facilities built after 1976 had secondary containment structures compared with $12 \%$ of the facility built between 1951 and 1976. The authors reported that most of the facilities built before 1951 did not have any such structures. It was reported that $35 \%$ of the pesticide mixing and handling operations take place within $90 \mathrm{~m}$ of a surface water body, and that the majority of facilities did not have storm water management plans. Mostaghimi et al. (1996) also reported that $38 \%$ of the facilities were unpaved and could not collect contaminated surface runoff. The close proximity of these facilities to water bodies may reduce chemical travel time, particularly during major storm events, and result in the transport of these chemicals, almost unaltered, to nearby surface water bodies. Overall, results from the survey conducted by Mostaghimi et al. (1996) indicated that a significant portion of the facilities in Virginia do not implement the practices necessary to minimize off-site transport of pesticides and fertilizers. There is a need to quantify the effects of structural and managerial BMPs implemented at agrichemical facilities on water quality. Results from such studies could provide the needed impetus for adoption of these BMPs by the agrichemical mixing and handling facilities to avoid costly cleanup and other regulatory measures.

The goal of this study was to evaluate the water quality impacts of BMPs implemented at an agrichemical mixing and handling facility located in Fauquier County, Virginia. A pre-BMP vs. post-BMP monitoring design was used to evaluate the water quality impacts of a combination of BMPs at the facility. Data collected over 10 years (1986-1995) were analyzed to evaluate the effectiveness of the BMPs in reducing the losses of selected pesticides, $\mathrm{N}$ and $\mathrm{P}$ to downstream water bodies.

\section{MeTHODOLOGY}

\section{BACKGROUND}

This study was conducted as a component of the Owl Run Watershed project (Mostaghimi et al., 1999), designed to evaluate the short and long term effects of animal waste management practices on stream water quality. The 1153 ha Owl Run watershed is in Fauquier County, Virginia, and is located 65-km southwest of Washington, D.C. (fig. 1). The primary land use within this drainage basin is agriculture, as the land area supports five major dairy, one replacement 


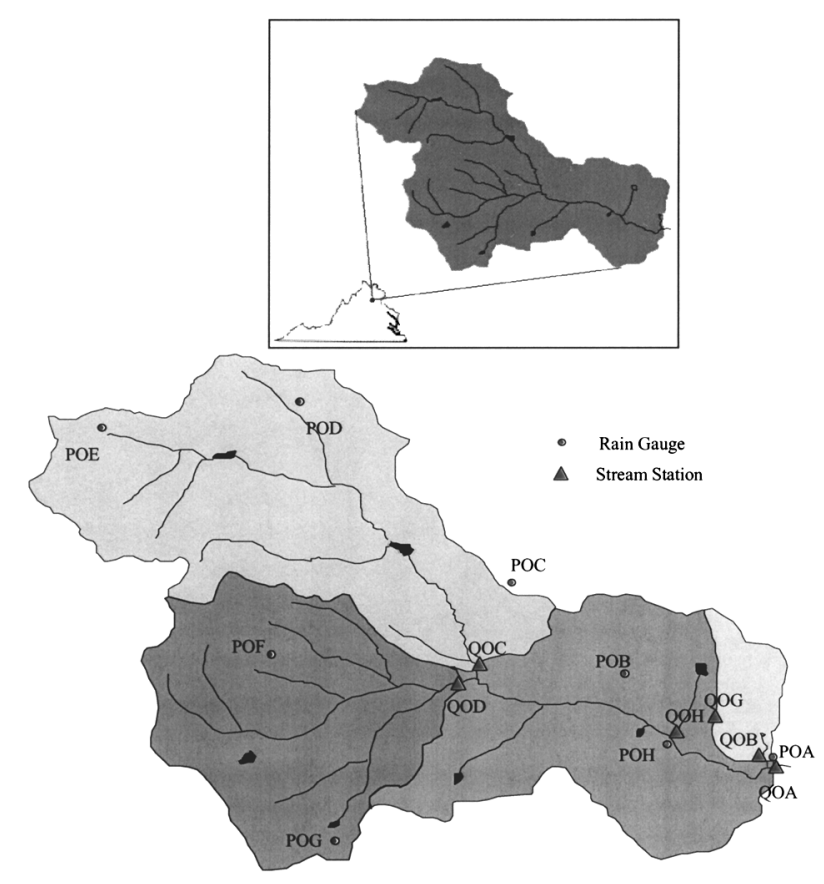

Figure 1. Location of monitoring stations within the Owl Run watershed (the inset on the top shows location of the watershed in Virginia): $Q=$ flow, $\mathbf{P}=$ precipitation, $\mathrm{O}=\mathrm{Owl}$ Run, and $\mathrm{A}-\mathrm{F}$ indicate different monitoring stations.

heifer, and three small beef cattle operations (Mostaghimi et al., 1989).

In 1986, high levels of atrazine and metolachlor were detected in samples collected at the watershed outlet, sampling station QOA (fig. 1). After inspecting the watershed, the source of this contamination was suspected to be a 2.0 ha agrichemical facility that stores and handles pesticides and fertilizers. The facility is located in Calverton, Virginia. After examination of the monitoring results, the facility manager agreed to implement a combination of structural and managerial BMPs in order to reduce chemical losses from the facility.

\section{SoIL, Land-Use, AND Climate}

The Owl Run watershed that contains the agrichemical facility is located in the Piedmont physiographic region of Virginia. The greater part of the watershed terrain is steep and rugged. The climatic conditions are those found in a humid continental-type region, with typically hot, humid summers and relatively mild winters. The average annual rainfall is approximately $104 \mathrm{~cm}$, the majority of which occurs during the spring. Nearly $70 \%$ of the watershed is used for agricultural purposes, including both crop and livestock productions. Twenty six percent of the watershed area is used for corn production (Mostaghimi et al., 1999). The remainder of the watershed includes residential, commercial, and forested areas.

Soils within the watershed are mostly shallow $(0.3-0.6 \mathrm{~m})$ silt loams, overlying Triassic shale. The soil at the site is Penn silt loam (undulating phase, no subsoil) found mostly in the upland areas of the watershed. Hydrologic characteristics of this soil include: medium to rapid drainage; medium runoff; occurrence of high water table; and poor water holding capacity. This strongly acidic soil is low in organic matter and is poorly supplied with nutrients mainly due to the inherent characteristics of the parent rock material (SCS, 1956).

\section{Pre and Post-BMP Conditions Pre-BMP Phase}

Initially it was suspected that the high concentrations of pesticides observed in the stream water samples could be due to a documented spill that had occurred in October 1983 at the facility. At that time, approximately 570 liters (2150 gallons) of bicep (a mixture of atrazine and metolachlor) were reportedly spilled at the facility. Cleanup activities were immediately undertaken and completed within a week after the spill. Since the half-life $\left(\mathrm{t}_{1 / 2}\right)$ of atrazine and metolachlor are, respectively, 60 and 90 days, it was concluded that the spill could not be the primary reason for high concentrations detected in 1986, 3 years after the spill. Another suspected source of pesticide was the adjoining railroad's herbicide application to control weed growth around the tracks, but it was determined that the type of herbicides used by the railroad were distinctly different from those handled by the agrichemical facility.

The agrichemical mixing and handling facility, which covers an area of about 2.0 ha, stored dry nitrogen components in a shed and liquid nitrogen and atrazine and metolachlor in storage tanks. A schematic of the pre-existing agrichemical facility is presented in figure 2 . The pond that formed behind the berm was used to collect runoff from the mixing and handling areas in a low-lying area near the loading site. This pond overflowed during large storm events. Runoff from the facility was routed through culverts to a stream leading to the Owl Run. The mixing and loading areas were not paved or roofed, and sprayer trucks were sometimes washed on the gravel parking lot. Furthermore, the facility lacked proper procedures/structures for disposing empty pesticide containers, resulting in an increased likelihood for the residual pesticides in the containers to be transported offsite through runoff.

\section{Post-BMP Phase}

The implementation of BMPs was initiated in February 1989 and completed in July 1989 for a total cost of about $\$ 32,000$ (Hilton Withers, personal communication, 29 July

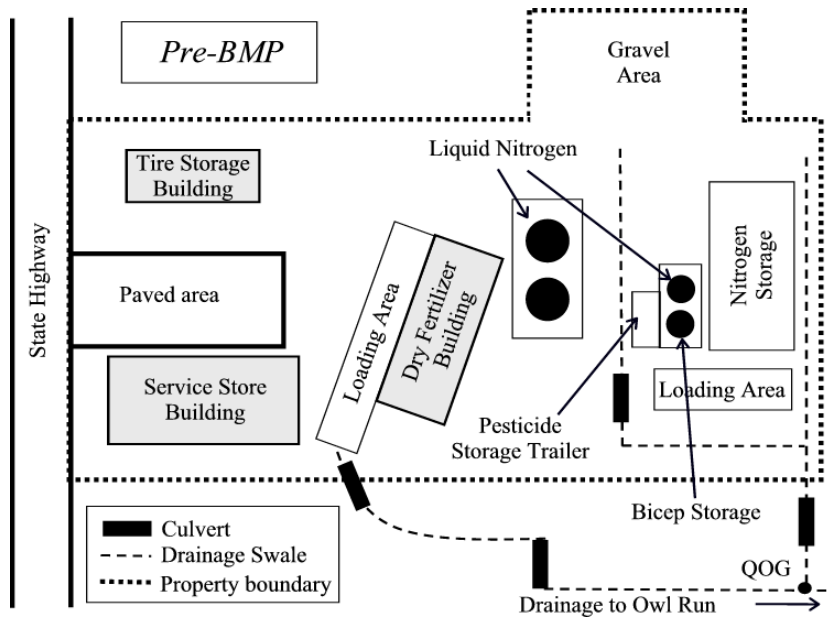

Figure 2. Agrichemical facility site plan prior to installation of Best Management Practices. 
1997). A storm water management plan was developed and implemented on the facility. Structural BMPs were adopted at the mixing/handling sites and chemical storage sites. Several managerial BMPs were also adopted. A schematic of the site in its post-BMP phase is shown in figure 3 .

The old dike and berm were removed, the loading area was paved, and the site was regraded so that all runoff was concentrated in one channel leading away from the loading areas. Ditches were then constructed to allow uncontaminated runoff water to bypass the agrichemical facility. Gutters and roofs were also placed on all structures in order to divert rainwater away from critical areas. Furthermore, secondary containment in the form of a completely contained masonry dike was placed around the bulk liquid fertilizer and pesticide tanks; and a mixing and handling concrete containment pad was constructed. The secondary containments were implemented as a safety backup and are used to prevent the movement of chemicals to the environment until accidental spills are cleaned up. In addition, a rinsate management plan was developed to minimize waste production and establish procedures for its disposal. Rinsate water tanks were installed on all spray trucks, and rinsate from the washing equipment was captured and reused in adjacent agricultural fields. Other managerial BMPs included frequent sweeping of the concrete apron at the fertilizer storage building, moving the packaged chemicals to a safer storage area, and disposing of containers in an appropriate fashion (triple rinsing and burning when applicable).

Adoption of structural and managerial BMPs considerably reduced the atrazine and metolachlor concentrations in the runoff originating from the facility. Diversion of the precipitation collected from the roofs away from the mixing/handling areas reduced the potential for pesticides being carried with the runoff. The potential for pesticide transport in the runoff from the facility was further reduced by regrading the site to route the flow away from the loading area. Regrading of the site increased the residence time of pesticide originating from handling/mixing activities at the site, thereby increasing the potential pesticide loss through volatilization, degradation, and adsorption. Construction of concrete pads at the mixing/handling site during the postBMP period prevented the direct contact of pesticide with the soil and therefore, reduced the potential movement of

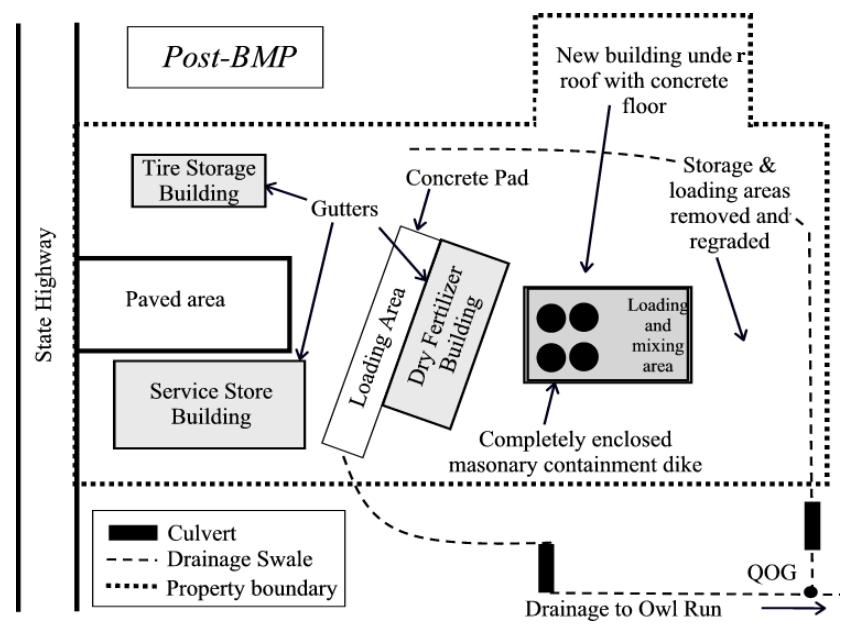

Figure 3. Agrichemical facility site plan after installation of Best Management Practices. chemical through runoff and leaching. Moreover, increased holding time of pesticide solution at mixing/handling pad considerably increased the potential for photodegradation of atrazine and metolachlor. The increased degradation, combined with field application of rinsate (collected through the sump) considerably reduced the net pesticides and nutrients mass available for transport to surface and ground water. These BMPs reduced the transitory concentration pulses both in the drainage from the facility (QOG) as well as in the Owl Run stream.

\section{Water Quality Monitoring}

Surface water grab samples were taken during selected storm events by the field observer at station QOG, located at the outlet of the subwatershed containing the agrichemical mixing and handling facility. The locations of the water quality sampling stations are shown in figure 1. Stream flow originating from the facility area is intermittent and occurs only during storm events. Station QOG is located approximately $500 \mathrm{~m}$ upstream of the Owl Run watershed outlet (QOA).

To identify the main source of high levels of pesticide concentrations at the Owl Run watershed outlet (QOA), grab water quality samples were also taken at the watershed outlet (QOA) and station QOH, which is located upstream of QOA, and before the point where drainage from the facility joined the Owl Run stream (fig. 1). Rainfall data were collected at a network of eight rain gauges located throughout the watershed (fig. 1).

Monitoring was initiated at station QOG in October 1986 and continued through November 1988 prior to implementation of BMPs at the facility (designated as pre-BMP period). BMPs were initiated in February 1989 and completed in July 1989. The post-BMP period monitoring continued from August 1989 until June 1996.

Immediately after sample collection, the water samples were shipped to laboratories at Virginia Tech and analyzed for total suspended solids (TSS), N, P, atrazine, and metolachlor. Nitrogen and phosphorus species analyzed included nitrate, total Kjeldahl nitrogen (TKN), filtered total Kjeldahl nitrogen (FTKN), orthophosphorus, and total phosphorus. The procedure and guidelines described in the Quality Assurance/Quality Control Project Plan for Owl Run Watershed Project (Mostaghimi, 1989) were followed to ensure proper data collection, handling, analysis, and reporting procedures. Extraction and analytical procedures were followed as outlined in the EPA approved standard operating procedures used by the Pesticide Residue Analysis Laboratory, Department of Biochemistry, Virginia Tech, and the Water Quality Laboratory, Department of Biological Systems Engineering, Virginia Tech. Analyses for atrazine and metolachlor were achieved through a general extraction procedure using a gas chromatograph with electron capture detector (Mostaghimi, 1999). The pesticide analysis procedures are contained in the Manual of Analytical Methods for the Analysis of Pesticides in Human and Environmental Samples (U.S. EPA, 1980). Nutrients were analyzed according to procedures contained in the Standard Methods for the Examination of Water and Wastewater (Eaton et al., 1995).

\section{Data Analysis}

Graphical and statistical analysis techniques were utilized for evaluating the water quality impact of BMPs implement- 
ed at the agrichemical facility site. Pesticide data collected at three sampling stations (QOA, QOG, and QOH) from 1986 to 1995 (except for QOH, which started in 1987) were included in the study, whereas nutrient data from 1987 to 1996 were examined. The data collected during the transitional period during which BMPs were installed (Feb. 89-July 89) were not included in the analysis. Because streams were dry at times, samples at all sites were only compared for those dates on which QOG was sampled.

When multiple samples were taken on the same day, values were reduced to a simple daily average. Non-detects were assigned half of their method detection limit (MDL) for analysis purposes. When the concentration was reported as below the MDL (due to higher instrumentation detection limits), the data point was also replaced by half of the MDL.

Time series plots and bar charts were utilized for studying the temporal trends in pesticide and nutrients over the entire study period. Frequencies of pesticide detection during the pre and post-BMP periods were computed to evaluate the BMP effects. Percent reductions in water quality variables were also computed to quantify the effects of BMPs.

Statistical analyses included computation of means and medians for water quality variables for pre-BMP and post-BMP periods for determining the extent of the water quality improvement. To determine whether the changes in the water quality variables were statistically significant, tests for examining monotonic and step trends were utilized. As a first step, Kolmogorov-Smirnov and Anderson-Darling (Anderson and Darling, 1954) distribution tests were used to examine the normality of the data. None of the variables were found to be normally distributed at the 0.05 significant level, and therefore, nonparametric tests were used to evaluate BMP impacts.

For examining the monotonic trends, water quality data for the entire study period (including the transition period) were used. The Mann-Kendall trend test (Kendall, 1975), including Sen's nonparametric slope estimator (Sen, 1968), was used to detect the overall trend in the annual median pesticide and nutrient data. This trend test is used when there are no cycles or seasonal effects in the data (Gilbert, 1987). Due to irregular sampling intervals, the numbers of data points available for each season were insufficient to test for seasonality. All of the trend analyses were performed using a modified version (Shukla et al., 1997) of the original routine developed by Engel and Gilbert (1987). The Mann-Kendall seasonal test was used to evaluate the overall and seasonal trend in precipitation data from the Owl Run watershed. The Mann-Whitney two-sample test (pre-BMP vs. post-BMP) was used to examine the step trend in the water quality variables.

\section{ReSults AND DisCuSSION}

The discussion of BMP impact results is divided into assessment of the extent of pesticide and nutrient contribution to Owl Run stream from the main watershed and its subwatersheds, followed by graphical and statistical analysis of water quality time series data to evaluate the effects of BMPs. The pre-BMP and post-BMP periods spanned from October 1986 to November 1988 (2.1 yrs) and August 1989 to June 1996 (6.8 yrs), respectively.

\section{Pesticide and Nutrient Contributions From the FACILITY}

Median concentrations of pesticides (atrazine and metolachlor) and nutrients ( $\mathrm{N}$ and $\mathrm{P}$ ) at the outlet of the main watershed (QOA) and subwatersheds (QOH and QOG) are presented in tables 1 and 2, respectively. Also presented in table 1 are chemical properties of the two herbicides. To examine the effect of the agrichemical facility (QOG) on the quality of water in the Owl Run streams, concentrations at two points, located upstream (QOH) and downstream (QOA) of QOG (fig. 1) were statistically compared using the Mann-Whitney test (table 1 and 2). Examination of table 1 reveals that medians of nutrient and pesticide concentrations at the outlet of the watershed (QOA) were higher than those at QOH. Median concentration of atrazine at QOA was more than one order of magnitude higher than those at $\mathrm{QOH}$; whereas median concentration of metolachlor at QOA was more than five times higher than those observed at QOH. In contrast to pesticides, no significant differences were found between the nutrient concentrations at QOA and $\mathrm{QOH}$ (table 2) indicating that nutrient discharges from the facility did not significantly impact the nutrient discharges from Owl Run watershed.

To study the relationship between the transport of nutrients and pesticides, the Spearman, Pearson, and Kendall measures of associations (Daniel, 1990; Minitab Inc., 1998) were utilized. The extent, as well as the statistical significance, of the correlation between nutrient and pesticide concentrations were examined. Results from the Spearman rank correlation procedure are presented in table 3. Two important inferences are drawn from the Spearman test results: a) atrazine and metolachlor levels are significantly correlated at all the three stations (QOA, QOG, and QOH); and b) correlation between pesticides and nutrients becomes significant after the drainage from the facility joins the Owl Run stream (correlations between pesticides and $\mathrm{NO}_{3}$ increased from 0.2 for QOH to 0.9 for QOA). Similar results were obtained from Pearson and Kendall tests (results not shown). The high correlation between atrazine and metolachlor is expected in light of the fact that these two herbicides are often applied in mixed formulations (e.g. bicep), therefore,

Table 1. Chemical properties, median concentrations, and results of Mann-Whitney (M-W) test for atrazine and metolachlor at monitoring stations QOA, QOG, and QOH.

\begin{tabular}{|c|c|c|c|c|c|c|c|c|c|}
\hline \multirow[b]{2}{*}{ Pesticide } & \multirow{2}{*}{$\begin{array}{c}\text { Soil } \\
\text { half-life } \\
\text { (days) }\end{array}$} & \multirow{2}{*}{$\begin{array}{l}\text { MCL } \\
(\mu \mathrm{g} / \mathrm{l})\end{array}$} & \multirow{2}{*}{$\begin{array}{l}\text { Solubility } \\
(\mathrm{mg} / \mathrm{L})\end{array}$} & \multirow[b]{2}{*}{ Persistence ${ }^{[\mathrm{a}]}$} & \multicolumn{3}{|c|}{$\begin{array}{l}\text { Median concentration } \\
(\mu \mathrm{g} / \mathrm{l})\end{array}$} & \multicolumn{2}{|c|}{$\begin{array}{l}\text { M-W test results for comparing } \\
\text { conc. at QOA and } \mathrm{QOH}\end{array}$} \\
\hline & & & & & QOA & $\mathrm{QOH}$ & QOG & Result & $\mathrm{p}$ value \\
\hline Atrazine & 60 & 3 & 33 & Moderately persistent to persistent & 2.41 & 0.16 & 103.70 & $\mathrm{QOA}>\mathrm{QOH}$ & 0.00 \\
\hline Metolachlor & 90 & 100 & 530 & Non-persistent & 0.75 & 0.14 & 230.46 & $\mathrm{QOA}>\mathrm{QOH}$ & 0.02 \\
\hline
\end{tabular}

[a] Non-persistent = hours to 12 weeks; moderately persistent $=1$ to 18 months; and persistent $=$ as much as 50 to 100 years (Briggs, 1992 ). 
Table 2. Median concentrations of nutrients and Mann-Whitney (M-W) test results at monitoring stations QOA, QOG, and QOH.

\begin{tabular}{|c|c|c|c|c|c|}
\hline \multirow[b]{2}{*}{ Nutrient } & \multicolumn{3}{|c|}{$\begin{array}{l}\text { Median concentration } \\
(\mathrm{mg} / \mathrm{l})\end{array}$} & \multicolumn{2}{|c|}{$\begin{array}{l}\text { M-W test results for } \\
\text { comparing conc. at } \\
\text { QOA and QOH }\end{array}$} \\
\hline & QOA & QOH & QOG & Result & $\mathrm{p}$ value \\
\hline Nitrate & 1.64 & 1.41 & 26.17 & $\mathrm{NSD}^{[\mathrm{a}]}$ & 0.31 \\
\hline Total N & 4.14 & 3.85 & 37.97 & NSD & 0.40 \\
\hline Ortho-P & 0.22 & 0.15 & 3.71 & NSD & 0.21 \\
\hline Total P & 0.57 & 0.59 & 6.85 & NSD & 0.09 \\
\hline
\end{tabular}

[a] Not significantly different.

depending on the precipitation characteristics, these two pesticides will be simultaneously transported through runoff. The second inference provides additional evidence to conclude that watershed $\mathrm{QOH}$ is the major source of nutrients, whereas the agrichemical facility is the major source of pesticides to the Owl Run stream.

\section{BMP Effects on Pesticide Transport}

The annual variability in the median concentrations of atrazine and metolachlor at QOA, QOH, and QOG is shown in figures 4 and 5 . The relative quantity and distribution of pesticide transport during pre-BMP and post-BMP periods is evident. Particularly important are the similarity in the atrazine and metolachlor distribution between sites QOA (main watershed outlet) and QOG (facility drainage outlet). Several explanations with different levels of certainty can be offered for the observed distribution of atrazine and metolachlor at QOA and QOG.

An examination of the distribution of pesticide medians during the 10-year period reveals that pre-BMP concentrations of atrazine and metolachlor are much greater than those during the post-BMP periods. Examination of the cyclic nature of the medians of atrazine and metolachlor at QOA after 1988 reveals that the periodicity of the cycle is one year (medians go up every other year). This periodicity is probably due to the nature of the crop rotation (corn-small grain-soybean) in the watershed. Atrazine and metolachlor are mainly used for weed control for corn. Therefore, the loadings of these two herbicides will increase during the year when the majority of the field crop area is under corn production. Examination of the time series plot of atrazine and metolachlor (figs. 4 and 5) at QOA and QOG reveals that the BMPs were effective in reducing the pesticide discharges at QOA and QOG since the medians of the two herbicides in the post-BMP phase do not come up to even the lowest levels observed before 1989 (pre-BMP period). The decline in post-BMP medians is more pronounced at the drainage outlet for the facility (QOG) (fig. 5).

To further examine the effects of BMPs on the pesticide discharges from the facility (QOG) as well as the main watershed outlet (QOA), the pre-BMP and post-BMP summary statistics for the two herbicides are presented in table 4. Adoption of BMPs drastically reduced the frequency of detection as well as the mean and median values (table 4). The mean atrazine and metolachlor concentrations during the post-BMP period decreased by more than $91 \%$ at the agrichemical facility outlet (QOG). This drastic reduction at QOG resulted in reduction of the mean atrazine and metolachlor levels at the main watershed outlet (QOA) by $52 \%$ and $77 \%$, respectively. Adoption of BMPs at the facility also decreased the maximum concentrations of atrazine and metolachlor at QOG by $91 \%$ and $41 \%$, respectively. The corresponding reductions in maximum observed concentration for metolachlor at QOA was 47\% during the post-BMP period. However, the maximum atrazine concentrations at QOA during the post-BMP period increased by $13 \%$.

Results from nonparametric trend and two-sample tests (pre-BMP vs. post-BMP) for evaluating BMP effectiveness are presented in table 5. The Mann-Whitney test indicates that the BMPs were effective in reducing the atrazine and metolachlor median concentrations for stations QOA and QOG (at the 0.05 level). The Mann-Kendall trend tests performed on the annual median concentrations of the two herbicides for the 10-year period revealed significant downward trend (at the 0.05 level) for both atrazine and metolachlor concentrations at stations QOA and QOG. Results for the monotonous trend tests (Mann-Kendall) agree with those for the step trend test (Mann-Whitney) (table 5). Rates of decline in atrazine and metolachlor concentrations at QOG were $64.70 \mathrm{ppb} / \mathrm{year}$ and 247.60 $\mathrm{ppb} / \mathrm{year}$; respectively, whereas the corresponding changes at watershed outlet (QOA) were $0.86 \mathrm{ppb} / \mathrm{year}$ and $1.23 \mathrm{ppb} /$ year. These results clearly indicate that the BMPs implemented at the agrichemical facility were very effective in reducing runoff concentrations of atrazine and metolachlor. The non-significant difference between the pre-BMP and postBMP levels for atrazine at QOH (table 5) and no overall trend over time (high $\mathrm{p}$ values and zero slope in table 5) for QOH confirms the previous conclusion that activities in the upper portion of the Owl Run watershed did not influence the pesticide concentrations observed at QOA and supports the hypothesis that the main source of pesticides was the agrichemical mixing and handling facility.

Two factors that might have introduced uncertainties in the BMP impact evaluation are the impact of precipitation trends over the monitoring period and the unequal duration of the pre-BMP and post-BMP periods and their possible impact upon the range of pollutant concentrations observed in the samples. The precipitation data (1986-1995) measured over the watershed by a network of eight rain gauges were analyzed for annual and seasonal trends. The Mann-Kendall seasonal statistical tests (at the 0.05 level) showed no

Table 3. Spearman rank correlation matrix for nutrient and pesticides at monitoring stations QOA, QOG, and QOH.

\begin{tabular}{|c|c|c|c|c|c|c|c|c|c|c|c|c|}
\hline & \multicolumn{4}{|c|}{ QOA } & \multicolumn{4}{|c|}{ QOG } & \multicolumn{4}{|c|}{$\mathrm{QOH}$} \\
\hline & Atrazine & Metolachlor & $\mathrm{NO}_{3}$ & Orth-P & Atrazine & Metolachlor & $\mathrm{NO}_{3}$ & Orth-P & Atrazine & Metolachlor & $\mathrm{NO}_{3}$ & Orth-P \\
\hline Atrazine & - & & & & - & & & & - & & & \\
\hline Metolachlor & $\begin{array}{c}0.88 \\
(0.01)^{[a]}\end{array}$ & - & & & $0.93(0.01)$ & - & & & $1.00(0.00)$ & - & & \\
\hline $\mathrm{NO}_{3}$ & $0.85(0.02)$ & $0.91(0.01)$ & - & & $0.22(0.54)$ & $0.20(0.57)$ & - & & $0.19(0.60)$ & $0.19(0.60)$ & - & \\
\hline Orth-P & $0.70(0.04)$ & $0.66(0.06)$ & $0.67(0.06)$ & - & $-0.20(0.57)$ & $-0.20(0.57)$ & $0.70(0.04)$ & - & $0.08(0.82)$ & $0.08(0.82)$ & $\begin{array}{c}0.60 \\
(0.09)\end{array}$ & - \\
\hline
\end{tabular}




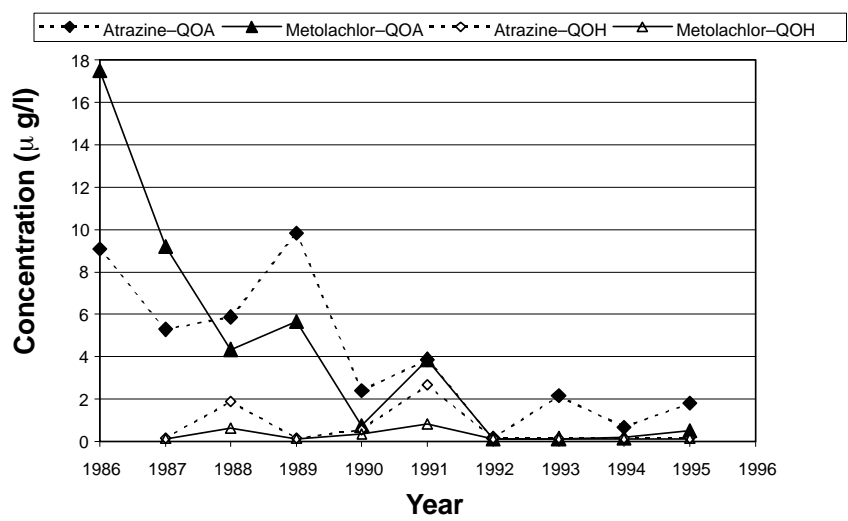

Figure 4. Time series plot for annual median concentrations of atrazine and metolachlor measured at monitoring stations QOA and QOH.

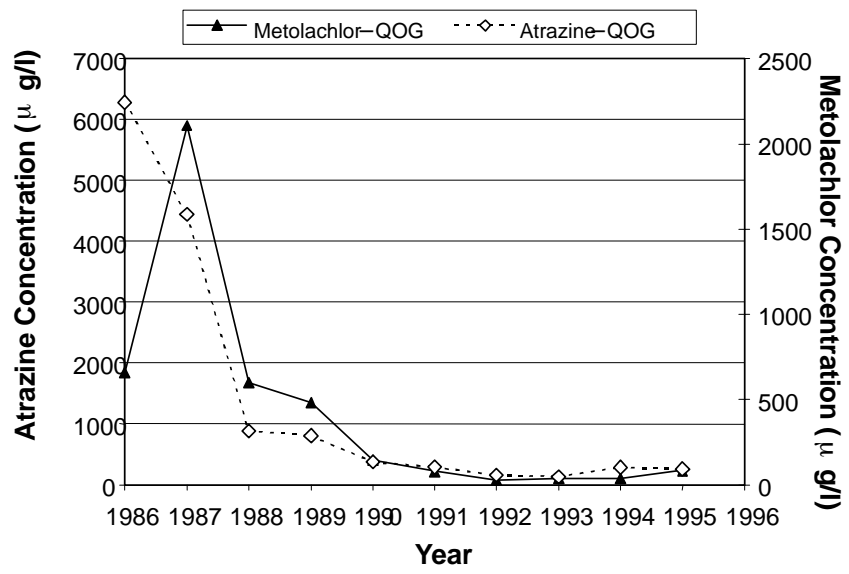

Figure 5. Time series plot for annual median concentrations of atrazine and metolachlor at facility outlet (monitoring station QOG).

Table 4. Pre-BMP (10/86-11/88) and post-BMP (8/89-6/96) summary statistics for atrazine and metolachlor collected at monitoring stations QOA, QOG, and QOH.

\begin{tabular}{|c|c|c|c|c|c|c|c|}
\hline \multirow[b]{4}{*}{ Pesticide } & \multirow[b]{3}{*}{ No. of samples $[\mathrm{a}]$} & \multicolumn{2}{|c|}{$\overline{\mathrm{QOA}}$} & \multicolumn{2}{|c|}{ QOG } & \multicolumn{2}{|c|}{$\overline{\mathrm{QOH}}$} \\
\hline & & Pre-BMP & Post-BMP & Pre-BMP & Post-BMP & Pre-BMP & Post-BMP \\
\hline & & 11 & 45 & 14 & 53 & 3 & 40 \\
\hline & & & & & & & \\
\hline \multirow[t]{4}{*}{ Atrazine } & Detection frequency $(\%)^{[\mathrm{b}]}$ & 100 & 71 & 100 & 87 & 100 & 33 \\
\hline & Mean $(\mu \mathrm{g} / \mathrm{l})$ & 15.09 & 7.22 & 2690.42 & 165.49 & 1.13 & 1.02 \\
\hline & Median $(\mu \mathrm{g} / \mathrm{l})$ & 5.88 & 1.66 & 1542.15 & 78.49 & 1.10 & 0.31 \\
\hline & Maximum Conc. $(\mu \mathrm{g} / \mathrm{l})$ & 80.18 & 92.19 & 17389.00 & 1452.00 & 2.16 & 8.62 \\
\hline \multirow[t]{4}{*}{ Metolachlor } & Detection frequency (\%) & 100 & 69 & 100 & 83 & 100 & 35 \\
\hline & Mean $(\mu \mathrm{g} / \mathrm{l})$ & 15.59 & 3.50 & 4579.00 & 402.16 & 1.37 & 0.65 \\
\hline & Median $(\mu \mathrm{g} / \mathrm{l})$ & 5.76 & 0.49 & 4172.30 & 187.10 & 0.40 & 0.29 \\
\hline & Maximum Conc. $(\mu \mathrm{g} / \mathrm{l})$ & 76.51 & 40.41 & 10337.00 & 6038.70 & 4.56 & 2.98 \\
\hline
\end{tabular}

[a] Same number of samples for atrazine and metolachlor.

[b] (Number of samples with detectable levels of pesticide / Total number of samples) $\times 100$.

Table 5. Results for the monotonic trend (Mann-Kendall) and step trend (Mann-Whitney comparisons) tests for nutrients and pesticides collected at monitoring stations QOA, QOG, and QOH.

\begin{tabular}{|c|c|c|c|c|c|c|c|c|c|}
\hline \multirow[b]{2}{*}{ Analyte } & \multicolumn{3}{|c|}{ QOA } & \multicolumn{3}{|c|}{ QOG } & \multicolumn{3}{|c|}{$\mathrm{QOH}$} \\
\hline & $\begin{array}{l}\text { Mann- } \\
\text { Kendall } \\
\text { p-value }\end{array}$ & $\begin{array}{c}\text { Mann- } \\
\text { Kendall } \\
\text { Sen slope }\end{array}$ & $\begin{array}{c}\text { Mann- } \\
\text { Whitney } \\
\text { comparison }\end{array}$ & $\begin{array}{l}\text { Mann- } \\
\text { Kendall } \\
\text { p-value }\end{array}$ & $\begin{array}{c}\text { Mann- } \\
\text { Kendall } \\
\text { Sen slope }\end{array}$ & $\begin{array}{c}\text { Mann- } \\
\text { Whitney } \\
\text { comparison }\end{array}$ & $\begin{array}{l}\text { Mann- } \\
\text { Kendall } \\
\text { p-value }\end{array}$ & $\begin{array}{c}\text { Mann- } \\
\text { Kendall } \\
\text { Sen slope }\end{array}$ & $\begin{array}{c}\text { Mann- } \\
\text { Whitney } \\
\text { comparison }\end{array}$ \\
\hline Atrazine & 0.02 & -0.86 & Pre $>$ Post & 0.00 & -64.70 & Pre $>$ Post & 0.45 & 0.00 & $\mathrm{NSD}^{[\mathrm{a}]}(\mathrm{p}=0.15)$ \\
\hline Metolachlor & 0.01 & -1.23 & Pre $>$ Post & 0.01 & -247.60 & Pre $>$ Post & 0.45 & 0.00 & Pre $>$ Post \\
\hline Nitrate & 0.11 & -0.19 & Pre $>$ Post & 0.59 & -0.66 & Pre $>$ Post & 0.59 & -0.10 & $\operatorname{NSD}(p=0.14)$ \\
\hline Total N & 0.01 & -0.82 & Pre $>$ Post & 0.47 & -1.95 & Pre $>$ Post & 0.06 & -0.74 & Pre $>$ Post \\
\hline Orth-P & 0.13 & -0.05 & Pre $>$ Post & 0.47 & 0.32 & $\operatorname{NSD}(p=0.20)$ & 0.15 & -0.03 & $\operatorname{NSD}(p=0.42)$ \\
\hline Total P & 0.00 & -0.16 & Pre $>$ Post & 0.86 & -0.26 & Pre $>$ Post & 0.04 & -0.09 & Pre $>$ Post \\
\hline
\end{tabular}

[a] No significant difference between pre-BMP and post-BMP median concentrations.

significant trend $(\mathrm{p}$ value $=0.314)$ over time. This supports the hypothesis that rainfall alone cannot account for the reduction in pesticide concentrations during the post-BMP period.

Multiple lines of evidence were provided in this article through examination of the data to conclude that BMPs adopted at the agrichemical facility were effective in reducing the atrazine and metolachlor concentrations both in the runoff from the facility as well as the outlet of Owl Run watershed (QOA). However, post-BMP levels of atrazine continued to be much higher than the Maximum Contaminant Levels (MCL) of $3 \mu \mathrm{g} / \mathrm{l}$ set by U.S. EPA. To facilitate close examination of the occurrences of atrazine and metolachlor levels under different concentration classes, frequency histograms for the pre-BMP and post-BMP periods are presented in figures 6 and 7 for QOG and QOA, respectively. A distinct shift towards lower concentration frequencies is clearly shown for the post-BMP phases at both QOG and QOA (figs. 6 and 7). The most distinct feature of figure 6 (QOG) is that none of the post-BMP atrazine detections exceeded $1500 \mu \mathrm{g} / \mathrm{l}$ concentration level in contrast to $50 \%$ of the pre-BMP samples that exceeded this level. A similar case is also observed for metolachlor concentrations above $5000 \mu \mathrm{g} / \mathrm{l}$ (fig. 6, QOG). Concentration ranges for 

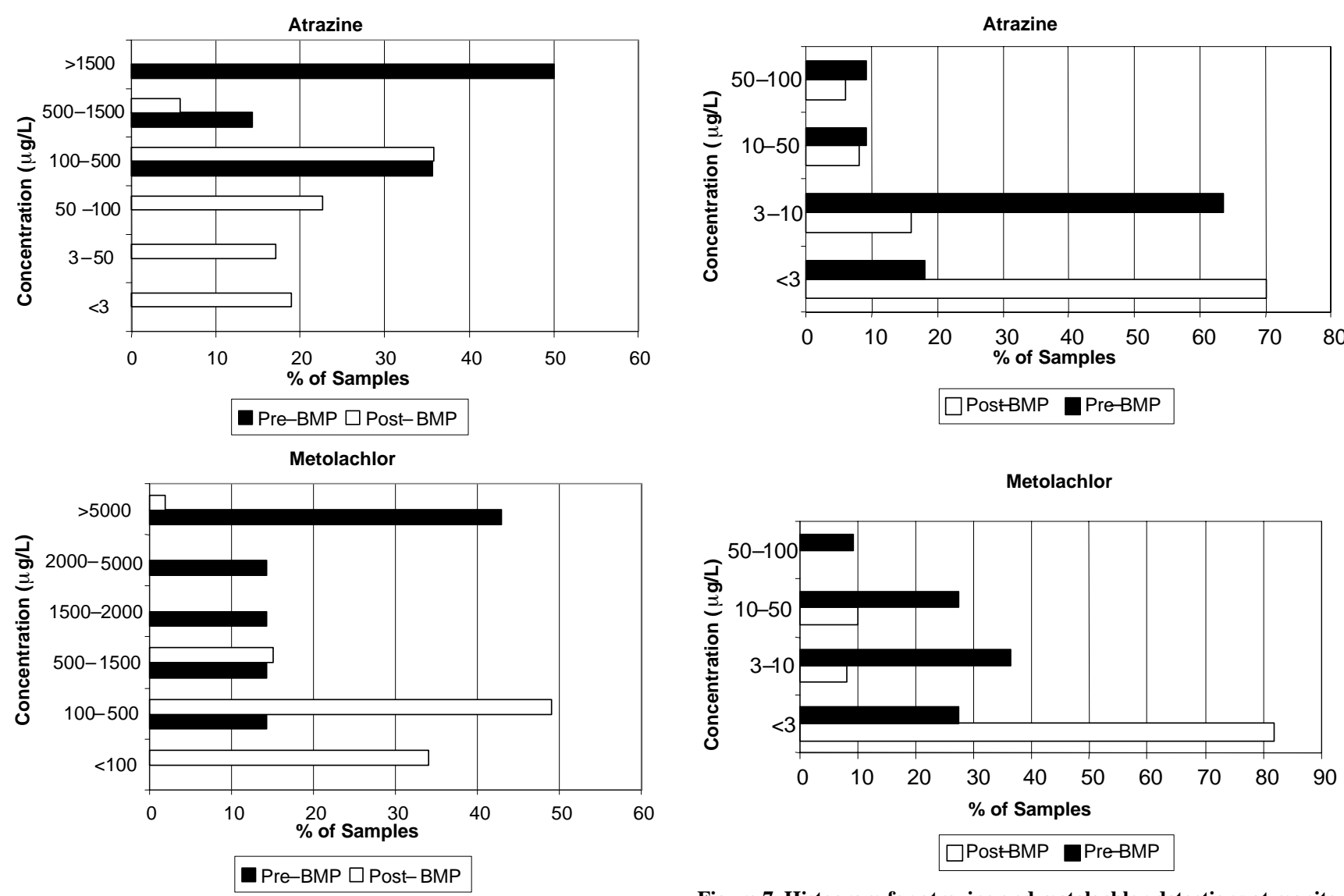

Figure 6. Histogram for atrazine and metolachlor detections at monitoring station QOG.

QOA (fig. 7) indicate that the percent post-BMP MCL exceedences for atrazine reduced from $80 \%$ during the pre-BMP period to less than $30 \%$ during the post-BMP period (fig. 7). Similar shift to lower concentrations are also shown for metolachlor for QOA. It is noteworthy that none of the samples collected at QOA had metolachlor levels in excess of its MCL of $100 \mu \mathrm{g} / \mathrm{l}$ for the entire study period (1986-1995).

Despite BMP implementation, approximately one-third of atrazine detections at QOA continued to exceed the MCL for this herbicide. High levels of atrazine have been shown to impair the water quality of streams. As mentioned before, growth of submerged aquatic vegetation is reported to inhibit presence of atrazine levels between 60 to $1040 \mu \mathrm{g} / \mathrm{l}$ (Kemp et al. 1982; Forney and Davis 1981). Examination of post-BMP frequency histogram (fig. 7) at the Owl Run watershed outlet (QOA) indicates that there may exist some potential for inhibition of submerged aquatic vegetation due to higher atrazine levels (>10 ppb). However, examination of time series plot for median atrazine levels for QOA clearly shows that values after 1992 do not exceed the atrazine MCL (fig. 4). In contrast to atrazine, metolachlor levels in the Owl Run stream never exceeded its MCL during the entire study period, therefore any potential effect on human health seems unlikely. The majority of QOG detections of both herbicides remained above their respective MCLs during the entire study period, although post-BMP concentrations of the two herbicides were reduced drastically.

Figure 7. Histogram for atrazine and metolachlor detections at monitoring station QOA.

\section{BMP EFFECTS ON NUTRIENT TRANSPORT}

Although the BMPs were implemented at the facility with the main objective of reducing the surface water transport of pesticides, the data collected on the $\mathrm{N}$ and $\mathrm{P}$ species at QOG (facility drainage), QOA, and $\mathrm{QOH}$ were also analyzed to examine if the BMPs had the additional benefits of reducing the nutrient levels in these streams. As noted before, the objective of the main Owl Run watershed study was to evaluate the impact of animal waste BMPs implemented in the upper watershed (upland of the facility) on the nutrient discharges from the watershed outlet (QOA). Evaluation of the impact of BMPs, implemented at the agrichemical facility, on the nutrient discharges from the main watershed outlet (QOA) was not possible due to the fact that the implementation of animal waste BMPs (upper part of the watershed) and the facility BMPs occurred during the same time period. Therefore, the discussion of the facility BMP impact evaluation is mostly limited to the analysis of the data collected at QOG.

An examination of medians of nutrient concentrations for the three sites indicates that nutrient concentrations at QOG are much higher than those at QOA and QOH (table 2), indicating the significant nutrient losses from the facility. Time series plot of annual medians of nitrate concentrations at QOG, QOA, and QOH are presented in figure 8. The cyclic nature of the plot for QOG is due to a combination of factors such as precipitation characteristics and variation in total mass of $\mathrm{N}$ and $\mathrm{P}$ handled at the facility in a particular year, depending on the acreage of specific crops (e.g. corn vs. 


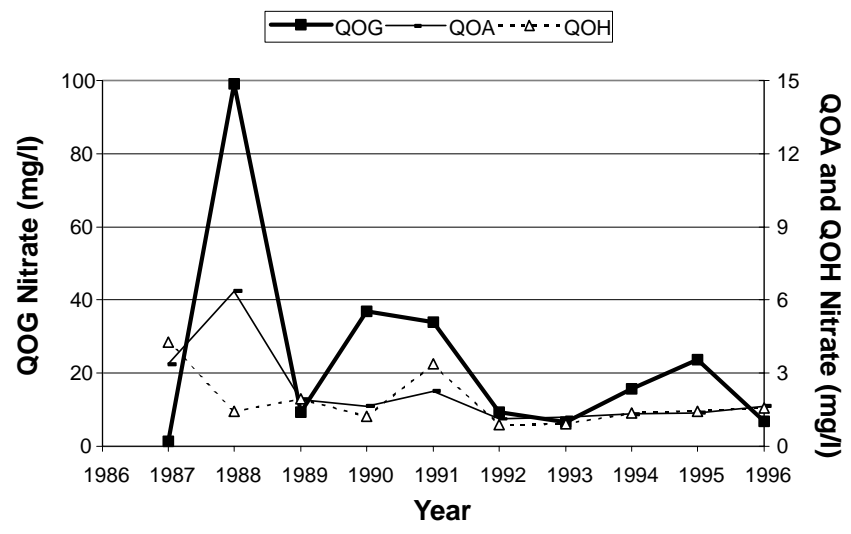

Figure 8. Time series plot for annual median concentrations of nitrate $\mathrm{N}$ measured at monitoring stations QOA, QOG, and QOH.

soybean) planted in the supply area. A comparison of QOA and QOG plots from 1987 to 1993 indicates a certain degree of match between the time series plot patterns for the two sites. This similarity between QOA and QOG may be an indication of some influence of the facility on the nutrient concentrations detected at the Owl Run watershed outlet. Examination of annual patterns of nitrate levels at QOG and QOA indicates that reduction in nitrate levels during the post-BMP period (after 1989) was not consistent.

To further examine the BMP effects on nutrient (nitrate, total nitrogen, orthophosphorus, and total phosphorus) discharges from QOA, QOG, and QOH, summary statistics for the pre-BMP and post-BMP periods are presented in table 6. Examination of the pre- and post-BMP statistics for QOA, QOG, and QOH clearly shows that net changes in nutrient levels during the post-BMP period are highest for QOG. It should be noted that the pre-BMP statistics might be biased due to the relatively smaller number of samples collected during this period (6 against 51) for QOG.

The Mann-Whitney test was used to determine if post-BMP nutrient levels were statistically less than the pre-BMP levels. The Mann-Kendall trend test was also employed to determine the direction as well as statistical significance of the nutrient trends over the study period. Examination of results from the Mann-Whitney and MannKendall tests for the three stations QOA, QOG, and QOH (table 5), indicates that nitrate, total $\mathrm{N}$, and total $\mathrm{P}$ discharges from the facility (QOG) during the post-BMP period were significantly less (at 0.05 level) than those during the pre-BMP periods. However, the Mann-Kendall trend tests for these nutrients at QOG do not show any statistically significant trend indicating that BMPs implemented at the facility failed to achieve significant reductions in the $\mathrm{N}$ and $\mathrm{P}$ discharges from the facility. Examination of pre-BMP vs. post-BMP test results for $\mathrm{QOA}$ and $\mathrm{QOH}$ for $\mathrm{N}$ and $\mathrm{P}$ indicates that results from the Mann-Whitney and MannKendall tests are in agreement for total $\mathrm{N}$ and total $\mathrm{P}$ levels (post-BMP < pre-BMP and significant downward trend, table 5). This agreement clearly signifies that reductions in the $\mathrm{N}$ and $\mathrm{P}$ levels at QOA and QOH were mainly a result of the animal waste BMP implementation in the watershed. Furthermore, since there was no statistically significant trend for nitrate at QOA and $\mathrm{QOH}$, it becomes clear that animal waste BMPs implemented in the upland areas of the watershed mainly reduced the organic N and P. Overall, changes in the nutrient discharges from the facility are not convincing enough to conclude that BMPs implemented at the facility had considerable impact on the nutrient discharges from the facility (QOG) as well as the main watershed outlet (QOA).

\section{Summary ANd CONClusions}

Effects of structural and managerial BMPs implemented at an agrichemical facility located within an animal production watershed in Virginia were examined in this study. Drastic reductions in pesticide concentrations were achieved through BMP implementation. Structural BMPs adopted at the facility were targeted at the mixing/handling and storage areas for the pesticides and fertilizers. Nonstructural BMPs included measures such as rinsate recycling. Before and after treatment watershed monitoring design was adopted for evaluating the effects of BMPs on the pesticide and nutrient discharges from the Owl Run watershed. Water quality samples collected at three sites for a period of ten years (1986-1995) were analyzed for pesticides and nutrients ( $\mathrm{N}$ and $\mathrm{P}$ species). One of the sites captured the runoff

Table 6. Pre-BMP (10/86-11/88) and post-BMP (8/89-6/96) summary statistics for nutrients at monitoring stations QOA, QOG, and QOH.

\begin{tabular}{|c|c|c|c|c|c|c|c|c|c|c|}
\hline \multirow[b]{3}{*}{ Nutrient } & \multirow[b]{3}{*}{ No. of samples } & \multicolumn{3}{|c|}{ QOA } & \multicolumn{3}{|c|}{ QOG } & \multicolumn{3}{|c|}{$\mathrm{QOH}$} \\
\hline & & $\begin{array}{l}\text { Pre- } \\
\text { BMP }\end{array}$ & $\begin{array}{l}\text { Post- } \\
\text { BMP }\end{array}$ & $\begin{array}{c}\% \\
\text { Reduction }\end{array}$ & $\begin{array}{l}\text { Pre- } \\
\text { BMP }\end{array}$ & $\begin{array}{l}\text { Post- } \\
\text { BMP }\end{array}$ & $\begin{array}{c}\% \\
\text { Reduction }\end{array}$ & $\begin{array}{l}\text { Pre- } \\
\text { BMP }\end{array}$ & $\begin{array}{l}\text { Post- } \\
\text { BMP }\end{array}$ & $\begin{array}{c}\% \\
\text { Reduction }\end{array}$ \\
\hline & & 12 & 62 & $\mathrm{NA}^{[\mathrm{a}]}$ & 6 & 51 & NA & 8 & 60 & NA \\
\hline \multirow[t]{2}{*}{ Nitrate } & Mean & 7.3 & 2.5 & 66 & 276.5 & 25.9 & 91 & 10.7 & 1.6 & 85 \\
\hline & Median & 3.8 & 1.5 & 61 & 90.4 & 20.0 & 78 & 2.8 & 1.5 & 46 \\
\hline \multirow{2}{*}{ Total nitrogen } & Mean & 17.2 & 5.2 & 70 & 347.8 & 54.1 & 84 & 15.6 & 3.6 & 77 \\
\hline & Median & 10.3 & 2.9 & 72 & 146.9 & 34.9 & 76 & 9.0 & 2.6 & 71 \\
\hline \multirow[t]{2}{*}{ Orth-P } & Mean & 1.6 & 0.4 & 75 & 15.7 & 7.5 & 52 & 0.3 & 0.2 & 33 \\
\hline & Median & 0.4 & 0.1 & 75 & 13.4 & 4.3 & 68 & 0.1 & 0.1 & 0 \\
\hline \multirow[t]{2}{*}{ Total phosphorus } & Mean & 3.5 & 0.7 & 80 & 20.6 & 8.9 & 57 & 0.9 & 0.5 & 44 \\
\hline & Median & 1.7 & 0.4 & 76 & 18.0 & 7.2 & 60 & 0.8 & 0.3 & 63 \\
\hline
\end{tabular}

[a] NA = Not applicable. 
originating from the agrichemical facility. The other two sites were located upstream and downstream of the point where the drainage from the facility joined the Owl Run. A variety of graphical and statistical techniques were utilized to evaluate BMP impacts.

Analysis of the water quality data confirmed that the agrichemical facility was the main source of atrazine and metolachlor discharges from the Owl Run watershed. The agrichemical facility was not a significant source of nutrients to the Owl Run. Effects of structural and managerial BMPs implemented at the facility were evident in drastic reductions in pesticide concentrations measured after BMP implementation. Based on the results of the study, the following conclusions were drawn.

- The BMP implementation at the agrichemical facility resulted in significant reductions of over $95 \%$ in both atrazine and metolachlor concentrations in the runoff from the facility (QOG).

- Reductions of $72 \%$ for atrazine and $91 \%$ for metolachlor were also observed at the main outlet of the Owl Run watershed.

- BMPs also reduced the percent of samples exceeding the atrazine and metolachlor MCL at the facility outlet (QOG) by $18 \%$ and $34 \%$, respectively.

- In contrast to pesticides, the effects of BMPs on nutrient discharge from the facility as well as the main watershed outlet could not be clearly established. Reductions in total $\mathrm{N}$ and $\mathrm{P}$ levels at the watershed outlet were mainly due to the animal waste BMPs adopted in the watershed, rather than the BMPs implemented at the agrichemical facility. Overall, BMPs implemented at the facility drastically reduced the pesticide movement to surface water. Despite the success of the BMPs in achieving the reductions, concentrations of atrazine continue to be at levels above its MCL.

The findings of this study could provide the needed impetus for BMP implementation at more than $55 \%$ of the agrichemical facility in Virginia where existing conditions are similar to the pre-BMP conditions at the facility considered for this study (Mostaghimi et al., 1996). Thirty eight percent of the facilities in the state which are unpaved and do not collect contaminated surface runoff may pose a potential threat to both surface as well as ground water. Limited surface and ground water monitoring should be undertaken at selected facilities to verify if the surface and ground water concentrations of pesticides are high. Such information is needed to evaluate the potential impact of these facilities on the downstream water quality.

\section{REFERENCES}

Ackerman, E. O., and A. G. Taylor. 1992. Pesticides in storm water runoff from agricultural chemical facilities. In Drainage and Water Table Control: Proc. 6th International Drainage Symposium, 161-168. St. Joseph, Mich.: ASAE.

Anderson, T. W., and D. A. Darling. 1954. A test of goodness of fit. J. Amer. Statistical Assoc. 49(266): 765-769.

Briggs, S. A. 1992. Basic Guide to Pesticides: Their Characteristics and Hazards. Washington, D.C.: Taylor and Francis

Buzicky, G., P. Liemandt, S. Grow, and D. Read. 1992. Agricultural chemical site remediation and regulations. In Pesticide Waste Management: Technology and Regulation, 234-243. J. B. Bourke, A. S. Felsot, and T. J. Gidding, eds. Washington D.C.: American Chemical Society.
CAST. 1994. Pesticides in surface and ground water. Issue Paper No. 2. Ames, Iowa: Council for Agricultural Science and Technology

Chesters, G., G. V. Simsiman, J. Levy, B. J. Alhajjar, R. H. Fathulla, and J. M. Harkin. 1989. Environmental fate of alachlor and metolachlor. In Review of Environmental Contamination and Toxicology. Vol. 110, 1-74. New York, N.Y.: Springer-Verlag.

Daniel, W. W. 1990. Applied Nonparametric Statistics. 2nd ed. Boston, Mass.: PWS-KENT Publishing Co.

Eaton, A. D., L. S. Clesceri, and A. E. Greenberg. 1995. Standard Methods for the Examination of Water and Wastewater. 19th ed. American Public Health Association. Baltimore, Md.: United Book Press, Inc.

Engel, D. W., and R. O. Gilbert. 1987. Testing for monotonic trends using Mann-Kendall, seasonal Kendall, and related nonparametric techniques. In Statistical Methods for Environmental Pollution Monitoring, 274-295. Appendix B. R. O. Gilbert, ed. New York, N.Y.: Van Nostrand Reinhold.

Forney, D. R., and D. E. Davis. 1981. Effects of low concentrations of herbicides on submersed aquatic plants. Weed Science 29(6): 677-685.

Gilbert, R. O. 1987. Statistical Methods for Environmental Pollution Monitoring. New York, N.Y.: Van Nostrand Reinhold.

Hoffman, W. L., and K. A. Cook. 1993. Stemming the Flow: Agrichemical Dealers and Pollution Prevention: Case Studies from the Great Lakes Basin. Washington D.C.: Environmental Working Group.

Kammel, D. W., R. T. Noyes, G. L. Riskowski, and V. L. Hofman. 1995. Designing facilities for pesticide and fertilizer containment. Midwest Plan Service. Ames, Iowa: Iowa State University.

Kemp, W. M., J. C. Means, T. W. Jones, and J. C. Stevenson. 1982. Herbicides in Chesapeake Bay and the effects of submerged aquatic vegetation. In Chesapeake Bay Program Technical Studies: A Synthesis, 503-567. Washington, D.C.: U.S. EPA.

Kendall, M. G. 1975. Rank Correlation Methods. London, U.K.: Charles Griffin.

Leonard, R. A. 1990. Movement of pesticide into surface waters. In Pesticides in the Soil Environment: Process, Impacts, and Modeling, 303-350. H. H. Cheng, ed. Madison, Wisc.: Soil Science Society of America.

Lounsbury, B. B. 1992. State pesticide disposal regulations and programs. In ACS Symposium Series: Pesticide Waste Management: Technology and Regulation, 8-19. Bourke et al., eds. Washington D.C.: American Chemical Society.

Minitab Inc. 1997. User's Manual, Version 11. State College, Pa.: Minitab Inc.

Mostaghimi, S. 1989. Quality assurance project plan for Owl Run Watershed/Water Quality Monitoring Project. Prepared for U.S. EPA, Region III. Report No. O-QA3-8906, Blacksburg, Va.: Virginia Polytechnic Institute and State University.

Mostaghimi, S., P. W. McClellan, and J. B. Lowery. 1996. Agricultural chemical mixing and handling facilities in Virginia: A statewide inventory. Commonwealth of Virginia, Department of Conservation and Recreation, Division of Soil and Water Conservation, Richmond Va. Blacksburg, Va.: Virginia Polytechnic Institute and State University.

Mostaghimi, K. M. Brannan, S. P. Inamdar, P. W. McClellan, and S. Shukla. 1999. Impacts of BMPs on surface water in the Owl Run Watershed. Report No. 0999OR-F. Submitted to the Virginia Department of Conservation and Recreation, Division of Soil and Water Conservation, Richmond, Va.

National Research Council (NRC). 1986. Pesticides and Groundwater Quality: Issues and Problems in Four States. Washington, D.C.: National Academy Press. 1993. Soil and Water Quality: An Agenda for Agriculture. Committee on Long-Range Soil and Water Conservation, 
National Research Council. Washington, D.C.: National Academy Press.

SCS. 1956. Soil survey for Fauquier County, Virginia. Soil Conservation Service, Unites States Department of Agriculture, and Virginia Polytechnic Institute and State University.

Washington, D.C.: U.S. Government Printing Office.

Sen, P. K. 1968. Estimates of the regression coefficient based on Kendall's tau. J. Amer. Statistical Assoc. 63(324): 1379-1389.

Senseman, S. A., T. L. Lavy, J. D. Mattice, E. E. Gbur, and B. W. Skulman. 1997. Trace level pesticide detections in Arkansas surface waters. Environ. Science and Technology 31(2): 395-401.
Shukla, S., A. C. Bruggeman, and S. Mostaghimi. 1997. TREND: An unpublished FORTRAN program for trend testing, Blacksburg, Va.: Department of Biological Systems Engineering, Virginia Tech.

U. S. EPA. 1980. Manual of Analytical Methods for the Analysis of Pesticides in Human and Environmental Samples.

EPA-600/8-80-038. Washington, D.C.: U.S. Environmental Protection Agency.

1994a. Standards for pesticide containers and containment: Proposed rules. Federal Register 26(9): OPP-190001, 40 CFR Parts 156 and 165. Washington D.C.: GPO.

.1994b. Pesticides Industry Sales and Usage: 1992 and 1993 Market Estimates. Washington, D.C.: U.S. Environmental Protection Agency 
